\title{
Que Modelo é Esse? as Alterações nos Processos de Capacitação de Recursos Humanos nos 20 Anos do Plano MARE
}

Which Model Is This? The changes in the human resource training processes in the 20 years of the MARE plan

Andrea de Oliveira Gonçalves Doutora em Integração da America Latina - Usp Universidade de Brasília - Professora http://lattes.cnpq.br/0002528252697017 http://orcid.org/0000-0001-7514-8139

andreagon@unb.br

Rogerio Luiz Alves dos Santos

Mestre em Gestão Pública/UnB Universidade de Brasília - Administrado http://lattes.cnpq.br/9845844788870091 http://orcid.org/0000-0002-6366-8011 rogerio@unb.br

João Abreu de Faria Bilhim Doutor Ciências Sociais/ULisboa Professor Catedrático/Universidade Lisboa http://lattes.cnpq.br/4203695171541419 http://orcid.org/0000-0002-3439-0591 jbilhim@iscsp.ulisboa.pt

Thiago Dias Costa Doutor Psicologia/ Univ Federal Pará Universidade Federal do Pará - Professor http://lattes.cnpq.br/1248194912228326 http://orcid.org/0000-0002-5443-5232 thiago@gestcomufpa.org

RESUMO: O Plano Diretor da Reforma do Aparelho do Estado foi implantado pelo governo brasileiro em 1995. Entre suas ações, instituiu a Política para o Desenvolvimento de Pessoal da Administração Pública. Essa ação trouxe as diretrizes da Política de Capacitação dos quadros funcionais do setor público do Brasil. Nesse sentido, este artigo analisa as principais alterações nos processos de capacitação da Universidade de Brasília (UnB), entre 1995 e 2015 , em face da literatura de gestão estratégica de pessoas. O estudo realizado é de natureza qualitativa; como técnica de coleta de dados, foram utilizados entrevista e documentos, ambos analisados por meio da análise de conteúdo e documental, respectivamente. Os resultados foram classificados em quatro modelos de administração pública abordados na literatura especializada. Os resultados acerca das condições de trabalho, planejamento, execução e controle da capacitação, bem como incentivos à qualificação, tendem a apresentar um ou mais modelos de administração pública adotados.

Palavras-chave: política de capacitação; modelos de administração pública; Plano Diretor da Reforma do Aparelho do Estado; Brasil.
ABSTRACT: The Master Plan for the Reform of the State Apparatus was implemented by the Brazilian Government in 1995. Among its actions, it instituted the Policy for Staff Development in Public Administration. This action resulted in the guidelines of the public service Training Policyin Brazil. Thus, this article analyzes the main changes in the training processes at the University of Brasilia (UnB), between 1995 and 2015 , in the face of the literature on strategic people management. The study is qualitative and as a data collection technique interview and documents were used, being evaluated through content and document analysis respectively. The results were classified into four models of public administration addressed in the literature. The results about the working conditions, planning, execution and control of the training policy as well as the incentives to qualification tend to have one or more public administration models adopted.

Keywords: training policy; public administration models; Master Plan for the Reform of the State Apparatus; Brazil.
RESUMEN: El Plan Director de la Reforma del Aparato del Estado fue implantado por el gobierno brasileño en 1995. Entre sus acciones, instituyó la Política para el Desarrollo de Personal de la Administración Pública. Esta acción trajo las directrices de la Política de Capacitación de los cuadros funcionales del sector público de Brasil. En este sentido, este artículo analiza las principales alteraciones en los procesos de capacitación de la Universidad de Brasilia (UnB), entre 1995 y 2015 , frente a la literatura de gestión estratégica de personas. El estudio realizado es de naturaleza cualitativa; como técnica de recolección de datos, fueron utilizados entrevista y documentos, ambos examinados por medio de análisis de contenido y documental, respectivamente. Los resultados se clasificaron en cuatro modelos de administración pública abordados en la literatura especializada. Los resultados sobre las condiciones de trabajo, planificación, ejecución y control de la capacitación, así como incentivos a la calificación, tienden a presentar uno o más modelos de administración pública adoptados.

Palabras clave: política de capacitación; modelos de administración pública; Plan Director de la Reforma del Aparato del Estado; Brasil.

Texto completo em português: http://www.apgs.ufv.br

Full text in Portuguese: http://www.apgs.ufv.br

\section{Introdução}

A construção de um novo modelo de Estado, exigência da agenda mundial nos anos 1990, é também o grande foco do contexto global de reformas da América Latina. Num contexto de globalização, desenhado na década de 80 , o grande desafio dos países ditos subdesenvolvidos à época, era enfrentar a economia internacional, tendo, para isso, que modificar suas políticas protecionistas e buscar uma nova forma de intervir nos planos social, político e econômico, sem ferir o avanço democrático conquistado pós-ditadura.

Correspondência/Correspondence: Andrea de Oliveira Gonçalves. Daniel Calbino Pinheiro. Endereço para correspondência: Faculdade de Economia, Administração e Contabilidade. Departamento de Ciências Contábeis e Atuariais. Universidade de Brasília. Campus Darcy Ribeiro - Prédio da FACE - Asa Norte. CEP: 70910-900 - Brasília - DF andreagon@unb.br 
Nesse sentido, a reforma da máquina administrativa, buscando um novo modelo de administração pública, tem sido elemento estratégico para a reconstrução de um Estado que

enfrente com eficiência, eficácia e efetividade os problemas desse cenário. Tendo essas tendências como diretrizes, o Governo Federal, buscando uma nova administração pública, elaborou o Plano Diretor da Reforma do Aparelho do Estado. Esse plano foi fundamental na identificação da necessidade de se reformar o aparelho burocrático ao trazer consigo princípios e características relacionadas a uma administração denominada gerencial, buscando modificar o paradigma organizacional do modelo weberiano (Souza, 2002). Foi, portanto, uma mudança estrutural profunda da máquina administrativa, transformando o modelo burocrático e adotando estratégias e tecnologias de gestão mais adequadas aos desafios contemporâneos.

Essa nova proposta de Administração surge nesse período como resposta ao desenvolvimento da tecnologia e à globalização da economia frente às novas atribuições econômicas e sociais do Estado. Para isso, a reforma precisou focar no fortalecimento do núcleo estratégico ocupado pela burocracia profissional.

Ao contrário do que se poderia imaginar, esse "fortalecimento" da força de trabalho do Estado, principalmente na esfera administrativa do Poder Executivo não se deu com a expansão quantitativa de sua força de trabalho. A evolução dos efetivos se deu em face da política de recursos humanos do governo e dos imperativos de ajustes fiscais.

Do texto extraído do Plano Diretor, cabe citar que uma das proposições era a modernização da administração burocrática, que primasse pela profissionalização do serviço público, ou seja, "de uma política de carreiras, de concursos públicos anuais, de programas de educação continuada permanente, de uma efetiva administração salarial, ao mesmo tempo em que se introduz no sistema burocrático uma cultura gerencial baseada na avaliação de desempenho" (BRASIL, 1995).

Para fazer frente a esse desafio específico, era imprescindível ao Governo atuar sobre o perfil da força de trabalho da administração federal. Era necessário, segundo Pacheco (2002, p. 80), "um quadro enxuto e altamente qualificado de funcionários, movidos pelo compromisso com resultados, e não apenas pelo cumprimento de formalidades legais ou obediente e acomodado com a perspectiva de estabilidade e aposentadoria integral". Sabiase, desde então, que a agenda de reforma seria longa. Nesta perspectiva, houve repercussões na Política de Capacitação por ocasião do advento do Plano Diretor de Reforma do Estado em 1995? Se houve, quais foram os impactos durante sua implementação e quais foram os principais efeitos observados na Universidade de Brasília? Este artigo, portanto, visa analisar as principais alterações nos processos de capacitação da Universidade de Brasília (UnB), entre 1995 e 2015, em face da literatura de gestão estratégica de pessoas.

O artigo está organizado em 6 seções. Além desta introdução, foi necessário discorrer sobre o cenário da administração pública no Brasil e seus avanços, bem como se apresentaram os modelos de administração pública presentes no país. Esses dois temas deram suporte para a reflexão sobre os processos de capacitação de recursos humanos no referencial teórico. A seção seguinte destaca o percurso metodológico e o processo de construção dos elementos que levam este artigo às respostas iniciais sobre o modelo adotado no Brasil. A quarta seção, descreve e discute detalhadamente os resultados encontrados acerca das principais alterações nos processos de capacitação. Por fim, a conclusão do artigo, em sua quinta seção, revela que modelo é esse de administração pública adotado pelo governo federal em 20 anos de reforma.

\section{Administração Pública Brasileira: do início ao Plano Diretor da Reforma do Aparelho do Estado}

Inicia-se a reflexão a partir dos modelos de Administração Pública experimentados e consolidados ao longo da história do Brasil, que podem ter influenciado o que se vivenciou na Universidade de Brasília (UnB) na área de Gestão de Pessoas, especificamente no que se refere à Política de Capacitação de seu quadro funcional nesses últimos 20 anos.

O modelo de administração adotado pelo Estado brasileiro, que se observa nos dias atuais, foi se estruturando e desenvolvendo ao longo de meados do século XX e início do século XXI. Esse Estado brasileiro que se vai constituindo, sobretudo, a partir da década de 1930, se apresenta fortemente imbuído na missão de transformar as estruturas econômicas e sociais da Nação, focando no desenvolvimento e tendo como alavanca os investimentos na industrialização do Centro-Sul brasileiro (Cardoso Jr., 2011). No entanto, enquanto os países já industrializados enfrentaram adequadamente as restrições financeiras e tecnológicas advindas do capitalismo originário, no Brasil, só muito recentemente, a Administração passou a encarar essas dificuldades com a seriedade necessária. Esse foi um dos fatores responsáveis pelo desenvolvimento tardio do país.

O contexto histórico, entretanto, obrigou o Estado brasileiro a correr contra o tempo, superando etapas no longo e difícil processo de montagem das bases materiais e políticas necessárias à missão de transformação das estruturas locais, visando o desenvolvimento nacional. A estruturação da Administração Pública no Brasil, não obstante algumas iniciativas, como a criação do Departamento Administrativo do Serviço Público (DASP), por Getúlio Vargas ou do Plano de Ação Econômico do Governo (PAEG), pelos militares, além das inovações contidas na Constituição Federal de 1988 (CF/88), padeceu de grande atavismo (Cardoso Jr., 2011).

A criação do Conselho Federal do Serviço Público Civil, em 1936, que se transformou em 1938 no Departamento Administrativo do Serviço Público (DASP), e sobreviveu até 1986, pode ser considerada uma primeira iniciativa de se inserir o país em um cenário mundial de administração mais desenvolvida. Durante sua existência, foram realizados os primeiros concursos públicos com características meritocráticas e criados órgãos para atuar em variados setores com definição de normas e estatutos. Contudo, cabe ressaltar, que as práticas herdadas do patrimonialismo 
continuaram a existir. Apesar de todo o esforço em universalizar o acesso ao emprego público com base no mérito, a ideologia que comandava as relações entre sociedade e Estado era ainda clientelista e empreguista, e daí que o número de funcionários extranumerários, contratados sem concurso, e por indicações pessoais, foi sempre superior aos estatutários (Gouvêa, 1994).

Tão logo o país conseguiu estabelecer os critérios e os procedimentos para a efetivação de uma administração burocrática, os movimentos seguintes de reorganização do aparelho estatal passaram a perseguir, contraditoriamente, a flexibilização de normas, ou desburocratização, ou, ainda, gerencialismo. Isso é verdade para as transformações realizadas no final dos anos 1960 , e para a reforma preconizada em 1995.

Um ponto em comum entre a Era Vargas e a Ditadura Militar é que as mudanças na Administração Pública foram implantadas para servir ao modelo de Estado como indutor do crescimento econômico. O desenvolvimentismo é a grande marca de muitos dos governos brasileiros, com poucas exceções. Um papel estatal ativo como ator econômico, exigiu a organização da máquina administrativa. Contudo, o caminho trilhado para a expansão do Estado como agente produtivo direto na era Vargas e no regime militar não é o mesmo. Entre 1930 e 1945, e entre 1951 e 1964, criaram-se novas empresas em diferentes setores com independência jurídica entre si. Já entre 1964 e 1974, o crescimento ocorre com a consolidação de grandes empresas em holdings e a proliferação de subsidiárias atuando em diferentes setores (dos Santos, 2006).

Ao final da década de 1970, o Brasil passou por um processo de redemocratização, em virtude de uma forte crise econômica, que se estabeleceu no Governo Militar (Kinzo, 2001). Provavelmente, em função da fraca experiência democrática nacional acumulada das décadas anteriores, podiam se observar fortes características de exclusão da sociedade civil do processo de formulação, implantação, implementação e monitoramento das políticas públicas brasileiras no período. A articulação entre governo e sociedade dava-se por meio de mecanismos políticos deletérios: o já citado clientelismo, o corporativismo e o insulamento burocrático.

Nos anos 80, o interesse na organização da Administração Pública sofreu um deslocamento dos termos do debate. $\mathrm{O}$ ataque maciço da sociedade ao setor público levou à procura de dispositivos até então somente utilizados na iniciativa privada para resolver os problemas burocráticos. A ênfase na necessidade de soluções para as ineficiências do setor público conduziram à aplicação de técnicas de gestão típicas do setor privado. Assim, a administração pública veio a ser cada vez mais descrita como gestão pública (Politt, 1990; Hood, 1991).

Segundo Cardoso Junior (2011), no Brasil neoliberal dos anos 90, o Governo vigente, para consolidar o primeiro Plano que ascendeu estabilidade econômica ao país depois de décadas de recessões - embora não sem impingir pesados fardos em contrapartida - começou a implantar, em 1995, ampla reforma administrativa do Estado e reforma dos direitos sociais. Essas ações surgiram no cenário brasileiro no momento em que uma nova crise cíclica atingia o sistema. E a solução para manter a lucratividade foi a desconstrução dos sistemas de bem estar social, por serem considerados os grandes causadores dos gastos públicos e das crises fiscais. Com o aparecimento de diversas lutas e manifestações da sociedade, ficou patente que as ações repressivas não eram mais adequadas ao momento, o que levou o Estado a assumir um papel mais regulador, direcionando sua intervenção diretamente nas questões de natureza econômica, social e política do país, a fim de manter sua legitimidade. Assim, surgem no final da década de 90 as primeiras agências reguladoras dos serviços de responsabilidade de prestação pelo Estado à sociedade.

Esse mesmo autor sustenta que nesse período, alinhada ao pacote mais geral de recomendações emanadas pelo Consenso de Washington, surge e ganha força uma agenda de reforma do Estado que teve, na primazia da gestão pública sobre o planejamento, um de seus traços mais evidentes (Cardoso Jr., 2011). E é neste contexto que se desenha a política de capacitação e desenvolvimento de inúmeras Instituições Federais no Brasil.

\section{Os Modelos de Administração Pública no Brasil}

Segue-se, portanto com a discussão teórica dos "modelos" de administração pública consolidados no Brasil e dos quais, em alguma instância, a Universidade de Brasília (UnB) pode ter sofrido influência na construção de sua política de recursos humanos.

$\mathrm{O}$ primeiro que se discute refere-se ao modelo patrimonialista delineado por De Paula (2005), Carvalho (2000); Nabuco (1977). Este modelo é caracterizado em um sistema patrimonialista, tornando a organização governamental muito mais um bem a ser explorado do que uma estrutura funcional a serviço do interesse público. Carvalho (2000) define o patronato como a presença clientelística na política brasileira. Segundo ele, na época de Rui Barbosa, no final do Império e início da República, a distribuição de favores por parte do governo tinha o nome de "patronato" e "filhotismo". O meio pelo qual se exercia o patronato era o empenho, ou seja, o "pistolão" (termo até hoje pronunciado nos debates populares), o pedido, a recomendação, a intermediação, a proteção, o apadrinhamento, a apresentação. Esta prática era e ainda é tão condenada quanto arraigada. Avaliações com base meritocrática e ações de melhorias profissionais estavam ainda longe do horizonte organizacional. As primeiras discussões nesse sentido são observadas a partir da era Vargas, já com desenho de um novo modelo de administração.

O novo desenho que se apresenta é chamado de modelo racional-legal, ou modelo burocrático weberiano, pois, Max Weber, nas obras A Ética Protestante e o Espírito do Capitalismo (2004) e Economia e Sociedade (1994), foi quem melhor analisou e definiu suas bases. Ramos (1983) conferiu à burocracia o significado de elemento característico de sistemas sociais relativamente avançados quanto ao desenvolvimento capitalista.

Weber (1994) definiu a burocracia como um agrupamento social em que rege o princípio da competência definida mediante regras, estatutos, regulamentos; da documentação; da hierarquia funcional; 
da especialização profissional, da permanência obrigatória do servidor na repartição, durante determinado período de tempo; e da subordinação do exercício dos cargos a normas abstratas. A burocracia assim concebida é um "universo evolucionário", elemento que caracteriza um grau relativamente alto do desenvolvimento social. Ao invés de ser um mal, como os marxistas a consideram, ela é, em Weber (1994), na visão de Guerreiro Ramos (1983), um fator de eficiência econômica e ingrediente indispensável de toda associação democrática. Com a criação do Conselho Federal do Serviço Público Civil, em 1936 e transformado em Departamento Administrativo do Serviço Público (DASP) em 1938, o Serviço Público Federal passou a ser regido pelas normas da burocracia racional-legal, embora no dia-a-dia ainda com práticas clientelistas do velho modelo patrimonial.

Nota-se, entre o primeiro (patrimonialista) e o segundo (burocrático) modelos analisados, certa evolução (mais teórica que prática) quanto a resoluções administrativas capazes de efetivamente estruturar uma nova organização de serviços. Entretanto, ao voltar o foco para a organização por meio de normas, o administrador esbarra no conceito negativo de burocracia, onde existe claramente um resíduo de atitude preconceituosa em relação ao assunto.

No que se refere à abordagem de gestão, o Gerencialismo enfatiza a adaptação das recomendações gerencialistas para o setor público (de Paula, 2005). Em outras palavras, no modelo gerencial, o ente público utiliza experiências consideradas bem sucedidas do setor privado na gestão da coisa pública. No Brasil, o Modelo de Administração Pública Gerencial teve sua origem num movimento internacional pela reforma do Estado, que se iniciou nos anos 1980 e se baseou, principalmente, nos modelos inglês e norteamericano. Seu projeto político, segundo De Paula (2005), enfatizava a eficiência administrativa e se baseava no ajuste estrutural, nas recomendações dos organismos multilaterais internacionais, e no movimento gerencialista, que tomou o mundo desde o final da década de 1970.

Outra característica desse modelo foi o início da abertura das instituições políticas à participação social. No entanto, observa-se um participativo mais no nível do discurso, com comportamento extremamente centralizador no que se refere ao processo decisório, à organização das instituições políticas e à construção de canais de participação popular.

Como aconteceu no Reino Unido e nos Estados Unidos durante a década de 1990, no Brasil ocorreu uma inversão política: o neoliberalismo de Collor foi substituído pelo pragmatismo da era FHC, com suas políticas progressistas orientadas para o mercado. Natural, portanto, que uma reforma de peso estivesse a caminho e que a proposta da mesma era de supostamente romper com o modelo burocrático de administração. Ao ser indicado para dirigir o MARE, Bresser-Pereira manifestou interesse pelas experiências realizadas em outros países e passou a estudá-las para formular uma proposta de adaptação do modelo ao contexto nacional (Bresser-Pereira, 1996, 1997, 1998). Este interesse, junto à aliança social-liberal, culminou na reforma do Estado, que ficou conhecida como "reforma gerencial" e o seu modelo de gestão, que recebeu o nome de "administração pública gerencial" (de Paula, 2005). Assim, em janeiro de 1995, o Plano Diretor de Reforma do Aparelho do Estado (Brasil, 1995) foi publicado. A Emenda Constitucional resultante do Plano, também conhecida como Emenda da Reforma Administrativa, foi promulgada em 1998 e tornou efetivas as mudanças estruturais que legitimaram a reforma gerencial.

Uma das principais inovações do Plano foi a reestruturação do aparelho de Estado em sua dimensão institucional. As atividades estatais foram divididas em "exclusivas do Estado": legislar, regular, fiscalizar e formular políticas públicas, de competência exclusiva da Presidência da República e os Ministérios; e as "não exclusivas do Estado": saúde, educação, assistência social e de escopo científico, além das atividades de apoio como limpeza, vigilância, transporte, manutenção, que foram encaminhados às empresas terceirizadas. $\mathrm{Na}$ perspectiva de Bresser-Pereira (1996, 1997, 1998), a nova administração pública se diferencia da administração pública burocrática, pois segue os princípios do gerencialismo. Ou seja, apresenta-se com uma administração profissional, autônoma e organizada em carreiras; apresenta indicadores de desempenho transparentes, há maior controle dos resultados e há ênfase no uso de práticas de gestão orientadas no setor privado.

Os modelos de administração apresentados até aqui, embora possam ser classificados numa ordem cronológica, não sofreram interrupções bruscas em suas existências, tampouco suas características são excludentes nas transições, visto que um novo modelo observado carrega em si características do (s) anterior (es), até que adquira uma identidade própria. No Brasil, a nova administração pública com abordagem das competências talvez ainda não possa ser definida como um "modelo" consolidado, posto que suas características só recentemente foram observadas no âmbito das instituições nacionais. Nos processos de reformas e contrarreformas administrativas propostas pelos líderes políticos, o que se observou até hoje foi o embate entre dois sistemas de forças: de um lado, a burocracia no sentido corporativo, centralizadora e, portanto, infensa às mudanças na organização e nas formas de operar do aparelho do Estado e, de outro, as forças inovadoras que encontram dificuldades para implementar suas propostas (Guimarães, 2000).

O modelo de gestão por competências teve origem na segunda metade do século $X X$, junto com o início da era do conhecimento e da informação. Foi um período de grandes transformações tecnológicas, sociais e econômicas; um processo de reestruturação produtiva apoiada no desenvolvimento científico e tecnológico e na globalização dos mercados (Lastres, 1999). Ferlie et. al. (1996) propõem a subdivisão do fenômeno em quatro "submodelos de gestão". Segundo os autores, que utilizaram a técnica analítica do "tipo ideal" weberiano, cada um desses submodelos representam momentos de ruptura com os modelos clássicos de administração pública. Destacam suas características focadas no impulso da eficiência; downsizing e descentralização; a busca da excelência; orientação para o serviço público. 
É neste pano de fundo, que se institui Política Nacional de Capacitação dos Servidores para a Administração Pública Federal direta, autárquica e fundacional. Naquele momento foi determinada uma nova visão gerencial de ações de capacitação, propondo tornar públicos os dados comparativos entre as instituições federais e sobre os gastos com capacitação dos órgãos.

\section{O Processo de Capacitação de Recursos Humanos}

Independentemente da corrente (ou modelo) que influencie o estilo de gerir seus efetivos, as organizações buscam os treinamentos como ferramenta padrão de preparação e incremento das competências profissionais de seu pessoal. De acordo com Freitas, Jabbour e Santos (2011), "os treinamentos tornaram-se prática formal nas organizações de maneira mais sistemática a partir da Administração Científica" (início do século $X X$ ), tendo sempre representado um recurso de aprimoramento de competências da mão de obra para o alcance de objetivos organizacionais e melhoria de desempenho agregado (Pilati, 2009).

A necessidade de preparar pessoas para desempenhar tarefas, seja em que nível, remonta da era industrial, com o surgimento das grandes corporações. Tendo evoluído para uma "gestão de pessoas", esta necessidade sempre foi influenciada por padrões de comportamentos, por estratégias de tomadas de decisões, caracterizando "modelos de administração". O modelo mais recente - gestão estratégica - é muito recente. No Brasil, somente a partir da década de 90 foram observados os primeiros vestígios da prática, adaptando experiências bem-sucedidas do mundo na década de 80

De acordo com Fonseca (2013), o campo de Treinamento, que era um objeto de estudo da psicologia na década de 60 , consolidouse como campo específico na literatura nas décadas seguintes, evoluindo para Treinamento e Desenvolvimento (T\&D) e, mais recentemente, Treinamento, Desenvolvimento e Educação (TD\&E). O campo foi se modificando e consolidando por meio de extensas pesquisas, voltadas para a melhoria da efetividade dos sistemas de treinamento organizacionais (Pilati, 2009). Os autores concordam que as atividades de TD\&E devem observar o comportamento humano na organização, para a sistematização de processos de planejamento e execução de ações educacionais e o desenvolvimento de tecnologia instrucional, compreendida como o conjunto de atividades que visam à efetividade do alinhamento do desempenho individual às necessidades organizacionais (Fonseca, 2013; Meneses; Zerbini; Abbad, 2010; Pilati, 2009).

Fonseca (2013) e Pilati (2009) entendem o sistema de treinamento sob uma perspectiva de influência recíproca de suas atividades com o contexto organizacional, o ambiente externo e as variáveis individuais. Esse sistema, segundo Borges-Andrade e Oliveira Castro (1996), é composto de três etapas: (i) avaliação de necessidades de treinamento; (ii) planejamento e execução; (iii) avaliação de treinamento.

Um processo eficaz de capacitação deve começar por identificar na instituição quais são as reais necessidades de treinamento. As atividades do campo de TD\&E são potencialmente estratégicas (Fonseca, 2013), mas podem se tornar um "balaio" de ações desarticuladas se não houver uma clara definição do que se pretende desenvolver em termos de habilidades e competências do servidor, individualmente; das equipes e, principalmente, do que se quer oferecer como produto final ao cidadão. Em outras palavras, deve-se alinhar o desempenho das equipes com os objetivos estratégicos da instituição.

A realização da Avaliação de Necessidades de Treinamento (ANT) é de suma importância para o planejamento das ações de capacitação a oferecer. É nesta primeira etapa que se define o escopo das ações, a priorização das atividades de acordo com as habilidades que a instituição necessita e de que ainda não dispõe para alcançar seus objetivos (Fonseca, 2013). É nesta fase também que se procura fazer uma projeção de que serviços os servidores treinados estarão aptos a desempenhar após a capacitação. Fazse, portanto, o caminho inverso, projetando o resultado do conhecimento na execução da tarefa.

O pouco conhecimento, a falta de perícia em realizar esta etapa, ou mesmo ignorar o procedimento, partindo para a elaboração de planos de capacitação com ações aleatórias é, segundo Fonseca (2013) e Menezes, Zerbini e Abbad (2010), "uma das razões para a baixa efetividade e o pequeno retorno dos investimentos em atividades de treinamento". A eficácia do sistema de treinamento depende, portanto, da realização efetiva da ANT, do planejamento instrucional para melhor formação de ações educacionais e de sua avaliação, de modo a permitir a readequação das metodologias e planos de treinamento em consonância com as verdadeiras necessidades organizacionais.

O "levantamento das necessidades de treinamento" implica no recolhimento de informações que terminam por expressar a impressão subjetiva de gestores e funcionários sobre o que seria necessário para a melhoria do desempenho (Fonseca, 2013). O termo levantamento, portanto, parece, à vista da literatura, restrito. Uma "análise de necessidades de treinamento" é um processo mais complexo, onde o gestor procura as "causas" das lacunas de desempenho, logo não sendo aplicado nas instituições com restrições de recursos e de pessoal. O campo considera, portanto, que uma "avaliação" das necessidades de treinamento seria mais adequada, visto que faz o levantamento, mas vai além, quando "projeta" os resultados da capacitação no desempenho final das atividades do servidor, sem, no entanto, se ater às "causas" das deficiências.

Cumprida a Avaliação das Necessidades de Treinamento, parte-se para o Planejamento das Ações, que deverão estar alinhadas, em primeiro lugar, com os objetivos primordiais identificados na avaliação de necessidades. No contexto estratégico, esses objetivos estão relacionados com a busca pela excelência e melhoria na qualidade dos serviços. Outro viés que é fundamental no planejamento é o atendimento ao que preconizam os dispositivos legais superiores que regulamentam as atividades de TD\&E, inclusive no que tange às demandas de recursos orçamentários para a execução. Deve-se certificar que todas as ações pretendidas sejam implementadas dentro das linhas de 
desenvolvimento da instituição, a fim de evitar desvios involuntários de esforços, dissonantes dos objetivos pré-negociados.

Tendo sido acordado que a atividade é essencial para a instituição e está apta a ser realizada, para cada ação deve ser discutido o público-alvo; as modalidades (presencial, semipresencial, à distância); as metodologias (bibliografia, recursos didáticos, formas de exposição, avaliações); a adequação de carga horária; o perfil de profissional mais adequado para ministrar; a disponibilidade de recursos para fazer frente às despesas; a data de realização; a certificação e a avaliação da ação.

\section{Procedimentos Metodológicos}

No caso em tela, ao se procurar esboçar a trajetória das ações de capacitação, treinamento e desenvolvimento destinadas aos servidores técnico-administrativos da Universidade de Brasília (UnB), a pesquisa ganhou um contorno histórico e o enfoque qualitativo mostrou-se como o mais apropriado para a pesquisa. Assim, adotou-se o ciclo proposto na metodologia utilizando o processo qualitativo (Sampieri et. al., 2006).

Embora o tema "capacitação no serviço público" seja frequentemente investigado e, apesar de haver vasta bibliografia sobre o assunto (Barbosa, 1981;Cunha, 1999; Cardoso Jr.; 2011; Camões, 2013; Fonseca, 2013; Weber et. al, 2015), a abordagem intrínseca da política de capacitação da força de trabalho da Universidade de Brasília não parece ter sido suficientemente debatida. Especialmente, porque na visão de Rizzatti e Dobes (2004, p.185), "a universidade é instituição singular, dividida em várias subculturas, caracterizada pela diversidade e ambivalência de objetivos". Assim, Cunha (1999) reforça que os estudos sobre gestão na universidade brasileira ainda são insuficientes e não alcançaram a profundidade que almejam. Neste sentido, desenvolver um estudo de caso sobre a política de capacitação de recursos humanos na UnB é oferecer aos diversos agentes da Administração Pública um relevante exemplo de gestão estratégica na perspectiva de compreender o capital humano como indispensável no processo de desenvolvimento e altos níveis de produtividade (Domingues, 2002). Em decorrência da substituição da Secretaria de Recursos Humanos (SRH) pelo Decanato de Gestão de Pessoas em 2014, a UnB segue a orientação do Ministério da Educação (MEC); do Ministério do Planejamento (MP); recomendação do Tribunal de Contas da União (TCU) e Controladoria Geral da União (CGU). Esta Universidade, com o segundo maior orçamento das Instituições Federais de Ensino Superior do país, passa a fazer parte de uma das 27 Instituições Federais de Ensino que acata tal recomendação. A implantação deste Decanato objetivou reformular os processos de trabalho, qualificar e motivar servidores. Passa, portanto, de uma estrutura técnica-operacional, para uma estrutura estratégica. Nesta perspectiva, importa saber se houve repercussões na Política de Capacitação da Universidade de Brasília por ocasião do advento do Plano Diretor de Reforma do Estado em 1995, justificando assim, a pesquisa nesta instituição.
Optou-se, na pesquisa que originou este artigo, a tipologia descritiva, que na visão de Danhke (1989), o objetivo é em descrever situações, acontecimentos e feitos, isto é, dizer como é e como se manifesta determinado fenômeno. Não foram construídas situações, foram observadas situações já existentes. No relato desenvolvido nesta pesquisa - evolução da política de capacitação da UnB - as variáveis independentes já haviam ocorrido e não era possível manipulá-las. Não se tinha controle direto sobre elas nem se podia influí-las sobre, porque já haviam acontecido, assim como os seus efeitos. Longe de qualquer ineditismo na abordagem do tema, foram observadas certas lacunas na literatura a respeito das políticas de capacitação a partir do Plano Diretor de Reforma do Aparelho do Estado de 1995.

Um primeiro esforço de pesquisa identificou variáveis que podem ser consideradas dificultadoras do processo de implementação da política de desenvolvimento de pessoas na Universidade de Brasília (UnB): escassez de recursos financeiros; falta de indicadores; ausência de registros mais consistentes sobre o desenvolvimento das ações, que dificultaram a descrição dos processos; equipes de capacitação reduzidas ao longo do período, entre outras. Entretanto, a exploração foi mais direcionada ao processo de capacitação em si. Procurou-se conhecer efetivamente como acontecem os passos das ações previstas nos portfólios. $\mathrm{E}$ como a equipe se reporta às direções no advento das dificuldades que se apresentam e, ainda, como as direções (e o Decanato) se reportam à Administração Superior para sanar os entraves.

Os dados foram coletados em duas etapas: entrevistas semiestruturadas e pesquisa documental. Como instrumento de coleta de dados primários, foram entrevistados 11 indivíduos pertencentes ao quadro funcional da organização, atuais ocupantes ou que já ocuparam função gerencial na área de capacitação ou Direção do Decanato/Secretaria. O objetivo das entrevistas foi conhecer o histórico, a estrutura e o funcionamento da Coordenadoria de Capacitação, identificar as principais ações de capacitação empreendidas ao longo do período e verificar como são executados os recursos destinados à área. O roteiro de entrevista foi desenvolvido com base na literatura e foi organizado em duas dimensões: (i) Modelo de Administração Pública e (ii) Política de Capacitação da UnB.

Neste artigo, a dimensão Política de Capacitação da UnB é o recorte utilizado para avaliar como se deu a política de Capacitação e Desenvolvimento dos Servidores da Universidade de Brasília e compreendeu as variáveis: base legal da política de capacitação; processos de Capacitação.

A seleção dos indivíduos entrevistados buscou tão somente priorizar as contribuições que eles pudessem trazer à pesquisa, da experiência acumulada na Instituição na área de investigação. O roteiro de entrevista foi constituído de (i) Questões gerais (gran tour); (ii) Questões para exemplificar; (iii) Questões de estrutura ou estruturais; (iv) Questões de contraste. Foram realizadas entrevistas com onze servidores ativos e aposentados que atuam/atuaram na Secretaria de Recursos Humanos (SRH), no Decanato de Gestão de Pessoas (DGP) ou, diretamente na 
Coordenadoria de Capacitação (PROCAP) da Universidade de Brasília. As entrevistas, sob a autorização dos indivíduos, foram gravadas em meio digital e posteriormente transcritas para análise. As entrevistas obtiveram a duração necessária para que fosse extraído o máximo de informações, seguindo um roteiro-guia, além de trazer questões que se mostraram adequadas. Assim, cada entrevista teve duração média de uma hora e meia a duas horas, totalizando treze horas e quarenta minutos de áudio digital e cento e vinte e duas páginas impressas.

Os documentos institucionais foram selecionados em diversos ambientes e no site da UnB. Foram consultados os documentos oficiais disponíveis, emitidos a partir de 1995 que totalizaram em 9.099 páginas, dos quais são atas, resoluções, relatórios de gestão e anuários. Toda a documentação coletada trata de questões que envolveram as ações de capacitação da Universidade de Brasília.

Os dados foram analisados por meio de análise documental e de conteúdo, a partir da proposição de Bardin (1977); Silva e Fossá ( 2013); Freitas, Cunha e Moscarola (1997). Cada variável analisada foi classificada conforme os quatro Modelos de Administração Pública: (1) Modelo Patrimonialista ; (2) Modelo Burocrático; (3) Modelo Gerencialista e (4) Modelo Estratégico.

O modelo patrimonialista tem suas características delineadas a partir da herança colonial; razão clientelista; observa-se o corporativismo e o personalismo. Os autores utilizados para esta caracterização são: De Paula (2005); Carvalho (2000); Nabuco (1977). O modelo burocrático trata de um modelo racional legal; weberiano; universo evolucionário e no Brasil configurou-se com a criação do DASP, mesmo assim observa-se como um patrimonialismo moderno. Os autores que sustentam a descrição são: Weber (1994 e 2004); Ramos (1977 e 1983); Prates (2007); Oliveira (1970); De Paula (2005); Mises (1944).

Já o modelo gerencialista, neste estudo, está sustentado na descrição dos autores De Paula (2005); Pereira (1997, 1998, 2015); Mare (1995); Fonseca(2013). Caracteriza-se por administração por carreiras; descentralização, competitividade, racionalização dos recursos; o uso de indicadores e observam-se práticas do setor privado. Eo modelo estratégico ou modelo de Administração por Competência, por ser um fenômeno relativamente recente, tem sido estudado e discutido em uma extensa revisão literária em vários países. Dedicaram-se a discutir esse modelo Guimarães (2000); Lastres (1999); Ferlie el al (1996); Pereira (1998); Fonseca (2013). De modo geral suas características revelam-se pelo impulso para a eficiência; downsizing e descentralização, bem como a busca da excelência.

\section{Resultados e Discussões}

Em busca de atingir níveis mais aprofundados de compreensão sobre a Política de Capacitação dos servidores da Universidade de Brasília (UnB), entre 1995 e 2015, a análise de conteúdo foi utilizada como, mais do que simples técnica de análise de dados, a verdadeira abordagem metodológica da pesquisa. Serviu como guia prático de ação, buscando captar os sentidos simbólicos de todos os registros a que se teve acesso. $\mathrm{Na}$ análise documental, mais do que o conteúdo explicitamente apresentado, procurou-se privilegiar o contexto (semântica, âmbito, tempo, pessoas envolvidas) em que os documentos foram elaborados, divulgados e aplicados.

Os processos de capacitação foram divididos em subcategorias: planejamento, execução e controle. Para fins de comparação, foi levantado o quantitativo de vezes que o tema "capacitação" foi citado nos últimos vinte anos, em comparação com outros temas que envolvem a gestão de pessoas ou de recursos humanos da UnB.

Os dados demonstraram uma baixa ocorrência de discussões no Conselho de Administração (CAD) de temas direta ou indiretamente ligados à política de capacitação das pessoas da UnB, dentro de um escopo de assuntos relacionados à gestão de recursos humanos da Instituição. Afastamentos para capacitação (6 vezes); capacitação de docentes (1); duração dos cursos (1), carga horária (1); educação formal (3); espaço físico para treinamento (1); gratuidade em cursos de pós-graduação (1); horário especial para servidor estudante (1); incentivos à qualificação (2); programa de treinamento e reciclagem (3); programa especial de treinamento, Programa de Educação Tutorial (PET) (1); questionamento sobre ações de capacitação (1). Os dados totalizaram 21 vezes em que os assuntos entraram em pauta e foram discutidos e parece ser pouco para um recorte temporal de 20 anos de reuniões do colegiado.

Embora tenha sido um dos focos principais da política de desenvolvimento de pessoas instituída no setor público brasileiro, pelo Plano Diretor de Reforma do Aparelho do Estado de 1995, considera-se que o assunto capacitação foi "redescoberto" a partir do advento da Lei n. 11.091, de 12 de 2005, que instituiu o novo plano de carreira dos servidores técnico-administrativos em educação vinculados às Instituições Federais de Ensino Superior do Brasil. A partir de então, o tema passou a ser mais frequentemente discutido, fato decorrente de movimentos dos próprios servidores, que naquele momento voltaram a receber incentivos financeiros ao apresentarem certificados e diplomas por ações de capacitação que tivessem realizado. Esse assunto é destacado e exemplificado na fala de entrevistados:

[...]O que acontece hoje? Hoje, a gente elabora o Plano Anual de Capacitação (PAC) com base no que a gente acha (E1)

[...]A questão é mais de planejamento e ter gente, tempo, e uma política da administração de superior que permita a esse setor planejar. Porque, assim, você planeja aí, daqui a pouco, muda tudo, aí seu planejamento já foi para o ralo (E1)

[...]Como são planejadas? A gente tem momentos de planejamento, por exemplo, no final do ano, depois que a gente executa, presta contas daquele ano, a gente começa um processo de planejamento para o ano seguinte. Toda equipe da PROCAP é envolvida com esse planejamento. Nós fazemos a LNT, nós fazemos consultas perguntando o tipo de interesse em determinados cursos, então, há o levantamento de necessidade de capacitação, nós fazemos, além disso, atendimento a demandas específicas (E7)

Este fato mostrou a necessidade premente, em 2005, de se construir uma nova oferta de cursos que atendesse ao disposto na Lei, de forma a incrementar os salários dos servidores, sem deixar de atender os interesses institucionais. Assim foi que o tema principal "Programa de Capacitação de Servidores" entrou em pauta 14 vezes nas reuniões realizadas entre 2005 e 2015. Ainda 
não parece ser quantitativo muito representativo, se comparado, por exemplo, à quantidade de vezes que o tema "Orçamento" (geral) foi discutido (26 vezes), praticamente em todas as reuniões. Entretanto, nota-se que houve, a partir do novo plano de cargos, um debate mais frequente e mais consistente quanto às ações de capacitação.

[...] a gente vai fazendo essas ações baseadas nas demandas, então, a gente faz um curso, por exemplo, de segurança no trabalho, a gente sabe que isso tem que ter constantemente, primeiros socorros, a gente sabe que isso tem que ter, mas chega lá as pessoas, ao fazer as avaliações, dão sugestões, pedem para ter uma turma, pela demanda a gente sabe a necessidade de ter uma segunda ou terceira turma, pela procura. Então, são cursos voltados para medir competências fundamentais e gerenciais que estão previstas também (E2)

[...] O que eu considero que é importante incluir e ter? Um programa de desenvolvimento gerencial que possa desenvolver pessoas para assumir funções gerenciais nas mais diversas áreas de atuação, então, possa formar gerentes para, por exemplo, gerenciar os processos das áreas acadêmicas que são processos parecidos. Então, nós teríamos uma linha de programa gerencial, uma linha para orçamento e finanças, digamos, uma linha para gestão de pessoas e ter uma linha que seriam competências gerenciais mais básicas, todo o gerente tem que ter independente de onde ele esteja, de qual o objeto, enfim (E1)

O tema capacitação foi bem mais frequentemente observado nas atas das reuniões da Câmara de Gestão de Pessoas (CGP) da UnB, entre 2013 (criação) e 2015.

A análise das falas dos conselheiros nos dois ambientes colegiados: Conselho de Administração (CAD) e Câmara de Gestão de Pessoas (CGP) demonstra diferenças significativas. Na pauta do CAD são incluídos pontos relacionados a todas as instâncias da Universidade. É compreensível, portanto, que os específicos sobre gestão de pessoas e capacitação se diluam frente ao universo de temas. Mas o que chama atenção é o caráter mais político das falas. A maioria dos discursos do CAD abordam os benefícios da Instituição em contar com equipes desenvolvidas e incentivam a qualificação, apenas do servidor técnico-administrativo. Os resultados aproximam-se das características do Modelo de Administração Estratégica, principalmente quando apontam a necessidade de se reverter o processo histórico de isolamento das organizações, fechadas em estruturas burocráticas e hierarquizadas, que têm resistência a qualquer tentativa de flexibilização e empreendedorismo (Ferlie et. al. 1996).

O Conselho, ao reconhecer a necessidade de mudar paradigmas, a fim de que a Instituição entregue uma gestão mais adaptada à evolução do Setor Público, o faz insistindo no desenvolvimento das competências específicas e gerenciais dos servidores, o que caracteriza um discurso estratégico. No entanto, não se observa em quase nenhuma das falas, proposições de desenvolvimento das condições necessárias para essa evolução. Neste aspecto, o que se poderia concretizar como boas práticas é dificultado pelos procedimentos excessivamente burocráticos, falta de investimentos mais robustos no desenvolvimento da política de capacitação e pela dificuldade de transformação dos discursos em ações práticas. Isso faz com que os registros que aparecem nas atas das reuniões do CAD revistam-se de um discurso estratégico, mas inviabilizado pela precariedade dos investimentos e pela baixa força política que o assunto desperta. Dessa forma, o discurso é por competências, mas as resoluções resultantes ainda podem ser classificadas como decorrentes do Modelo de Administração Burocrática. Ou seja, observa-se sua base na racionalidade legal na perspectiva weberiana como registrado por Weber (1994) e Ramos (1983).

Em contraponto, as discussões da Câmara de Gestão de Pessoas (CGP) mostram-se mais pautadas em propostas efetivamente estratégicas. Embora também reconheçam a necessidade de incrementos, a linguagem utilizada é quase exclusivamente técnica. As pautas relacionadas demonstram que, às intenções aliam-se proposições de ações factuais. Observase um delay entre o discurso e a implantação das ações, mas as condições de como fazer acontecer são efetivamente colocadas no âmbito da Câmara.

A criação da Câmara de Gestão de Pessoas (CGP), vinculada ao DGP, em 22 de maio de 2013, por meio da Resolução do CAD n. 6, foi fator relevante na discussão do tema capacitação da UnB. A partir de então, foram incluídas sistematicamente nas reuniões, discussões sobre a política de gestão de pessoas da Universidade, com destaque para os assuntos relacionados à capacitação dos servidores.

Ao analisar a trajetória das gestões, observa-se que as equipes que estiveram à frente do Decanato de Gestão de Pessoas (DGP) nos últimos cinco anos buscaram retomar a agenda imposta a partir da Reforma Diretor de Reforma do Estado, orientando seus trabalhos no sentido de alinhar as ações às diretrizes dos Decretos de desenvolvimento da carreira do servidor e demais dispositivos legais.

O esforço de se adaptar à nova dinâmica de desenvolver capacitação na Instituição fica mais evidente nas falas da equipe da Coordenadoria de Capacitação (PROCAP), ao contrário da Administração Superior e mesmo nas falas do Decanato de Gestão de Pessoas. No âmbito interno, as ideias parecem mais avançadas, mais direcionadas às características do Modelo de Administração Estratégica (Guimarães, 2000; Lastres, 1999; Ferlie et al,1996; Pereira, 1998; Fonseca, 2013). No entanto, a equipe esbarra em diversos níveis de dificuldade, entre eles a falta de experiência de trabalhar dentro de uma rotina organizada de desenvolvimento de competências, o que pode ser observado pelos relatos de como são realizados os processos de capacitação (planejamento, execução e controle). No caso do planejamento das ações, os procedimentos parecem seguir características do Modelo de Administração Burocrático onde as normas estabelecidas robotizam procedimentos e dificultam a mensuração de sua efetividade (Weber, 1994 e 2004; Ramos, 1977 e 1983; Prates, 2007; Oliveira,1970; De Paula,2005; Mises,1944).

No que tange à execução e controle dos Processos de Capacitação tomou-se como referência os dados apresentados no Relatório de Gestão da Diretoria de Capacitação, Desenvolvimento e Educação (DCADE) do DGP, relativo ao exercício de 2014. De acordo com o Relatório de Gestão, a Coordenadoria de Capacitação - PROCAP executou seu Plano Anual de Capacitação (PAC), onde estavam previstas ações de capacitação segundo as linhas de desenvolvimento estabelecidas no Decreto n. 5.825/2006. 
As ações de capacitação foram oferecidas em duas modalidades: presencial e a distância $(\mathrm{EaD})$. Referente à modalidade presencial, as ações de capacitação foram realizadas em seu planejamento e execução, chamadas de ações de capacitação internas, ou por meio da viabilização da participação dos servidores em cursos, congressos e simpósios e congêneres, oferecidos por pessoas jurídicas diversas, que denominam ações de capacitação externas. As ações de capacitação externas foram ofertadas por meio de editais, que selecionaram projetos de capacitação para o desenvolvimento de competências específicas e também sob a demanda das unidades, por meio de chamadas públicas. No tocante à modalidade à distância, as ações de capacitação foram oferecidas por meio de parceria entre a Coordenadoria de Capacitação (PROCAP) e o CEAD (Centro de Educação a Distância), ou por meio de editais de competências específicas.

Em 2014 foram ofertadas 12 ações de capacitação à distância e 64 na modalidade presencial. De acordo com a Diretoria, para que a modalidade EaD cresça e atinja um público mais significativo, são necessários maiores investimentos para tornar o processo de construção e oferta de cursos mais independente da infraestrutura de parceiros, capacitar mais a equipe EaD - PROCAP, entre outras providências que se fazem necessárias (DCADE-DGP, 2014).

Quanto aos treinamentos presenciais, embora tenha havido maior oferta em termos de número de ações de capacitação e consequentemente de hora/aula, faz-se necessário aprimorar os processos de trabalho, para então dimensionar as reais necessidades de pessoal. O Relatório diz que muitas dificuldades foram encontradas durante o ano de 2014, tais como organização da equipe e dos processos/rotinas de trabalho, mudanças sucessivas de gestão, e dificuldades de conseguir salas de aula e laboratórios para viabilizar as ações de capacitação.

No total, 2.072 vagas em ações de capacitação foram oferecidas pela Coordenadoria de Capacitação (PROCAP). Observou-se que, das 346 vagas vinculadas à linha de desenvolvimento gerencial, apenas 69 são ocupadas por servidores com algum tipo de função gratificada. Esse dado chama a atenção para a necessidade premente de se conhecer as necessidades específicas desse público. Parece adequado supor que um programa de desenvolvimento gerencial poderia dar maior visibilidade aos cursos desta linha de desenvolvimento.

Embora tenham sido realizadas 1647 capacitações em 2014, foram capacitados 890 servidores. Isto significa que um mesmo servidor pôde fazer mais de um curso no ano 2014. Entre os gerentes a moda sinalizou para a participação em apenas uma capacitação. Os demais servidores participaram de duas ações de capacitação.

Especificamente sobre os mecanismos de controle, os resultados demonstraram que são realizados tanto ex ante (elaboração de normas, definição de orçamento para capacitação), quanto ex post (prestação de contas, relatórios gerenciais, avaliações dos treinamentos). As observações dos participantes sobre esses mecanismos de controle apontaram uma tendência de
Modelo de Administração Patrimonialista (1995-2010) e Modelo Gerencial (2010-2015). Isso quer dizer que o início do setor de capacitação foi marcado pela quase ausência de recursos para investir. Além disso, o orçamento de capacitação era controlado pelo Centro de Seleção e de Promoção de Eventos (CESPE), que repassava certo numerário à Coordenadoria de Capacitação (PROCAP). A criação da PROCAP sinaliza para uma característica de centralização e controle tratado no Patrimonialismo Moderno.

A partir da evolução da estrutura de gestão da UnB na última década, nota-se um esforço empreendedor nas atividades de controle da capacitação, principalmente na racionalização dos recursos financeiros, na organização dos processos para respostas a auditorias e na preocupação com a transparência. São características que se assemelham ao Modelo Gerencial.

De maneira crítica, os entrevistados colocam esta questão, quando afirmam que a PROCAP era um dos Centros de Custo que tinha por hábito devolver recursos anualmente. Isto devia-se, principalmente, à baixa capacidade de execução das atividades de capacitação, na medida em que os recursos destinados à área ainda são limitadas às operações de custeio, mas não podem ser utilizados como investimento, por exemplo. Outro fator é a já discutida precariedade das condições de trabalho. São adversidades de gestões que tendem a reproduzir os Modelos Patrimonialista e Burocrático, demonstradas nas falas dos entrevistados:

[...]Um dos grandes problemas do início da Política de Capacitação na UnB $(1995)$ pode ser creditado à total e absoluta falta de recursos financeiros, de equipamentos, de materiais, de espaço físico e de pessoal para o setor. Ou seja, o PROCAP foi criado para ofertar cursos sem custos. Depois de algum tempo à frente da gestão do PROCAP eu descobri que os recursos financeiros existentes eram utilizados pelo CESPE, que ainda não era a potência de hoje. Nós dependíamos do CESPE para praticamente tudo. E também da "ajuda" da Editora, do Hospital Universitário e de outros Centros de Custo. Contávamos com eles para quase tudo. Dependíamos do grau de amizade e da boa vontade dos colegas desses órgãos para planejar a nossa oferta (E5)

[...] Só que isso foi feito no serviço público todo, não só nas Universidades, que todas eram federais, era para todo o serviço público. O que aconteceu? Não tinha dinheiro para atender. Por exemplo, nós nunca recebemos destaque por conta desse plano para que pudéssemos desenvolver essas ações dentro da Universidade de Brasília (E8)

Nos últimos 5 anos, a partir da reestruturação da área de gestão de pessoas, parece ter havido um esforço das equipes de desenvolvimento no sentido de um novo fôlego para o setor de capacitação. Pelos relatos, continuamente são buscadas alternativas de execução das ações de forma mais ágil e criativa, ainda que o planejamento e o controle ainda não acompanhem essa nova tendência. Revelam-se, aí, improvements observados nos Modelos Gerencial e Estratégico.

Por fim, ao tratar da categoria "Incentivos à Qualificação" os modelos patrimonialista e estratégico se apresentaram em decorrência das características extraídas das falas dos entrevistados. O fato da capacitação não ser vista como atividade estratégica por parte da maioria das chefias, às vezes inviabilizando a participação do servidor nos cursos, ou exigindo que o mesmo reponha as horas, é característica latente do modelo patrimonialista centralizador. As ações da equipe de capacitação em investir 
recursos cada vez mais vultosos nos programas, bem como as previsões legais de licenças e afastamentos direcionadas aos técnicos administrativos, podem ser relacionadas ao Modelo Estratégico. Destaca-se que as falas dos entrevistados sugerem o modelo adotado:

[...]Naquela época (1995) o único (e saudável) incentivo para quem se qualificava na UnB era a melhoria no seu desempenho profissional e o aproveitamento pessoal. Ou seja, a pessoa crescia e se desenvolvia, enquanto profissional e enquanto gente (E5)

[...]Antes as pessoas não procuravam muito, praticamente, a maior parte estava no último nível de capacitação, agora não. Agora eles procuram saber como é que é a progressão, como é que é o incentivo à invistam nisso, então, eu acho que falta muito investimento por parte da administração superior (E2)

[...]Muitas dessas pessoas conseguem depois afastamentos para terminar a sua dissertação, isso é incentivo, conseguir licença capacitação de 3 meses para fazer sua redação em casa, isso é incentivo $(E 7)$

No caso da carreira dos servidores técnico-administrativos em educação (TAE), responsáveis pelo desenvolvimento da área-meio da Instituição, os desempenhos esperados apresentam um rol de competências mais amplo, dependendo da atividade que lhe são atribuídas. Instituído por meio da Lei n. 11.091, de 12 de janeiro de 2005, o Plano de Carreira dos Cargos Técnico-Administrativos em Educação (PCCTAE), "abriu” possibilidades de progressão em uma carreira que há tempos mostrava-se engessada. Nesta altura, as IFES padeciam de mais de 10 anos sem renovação de seus quadros administrativos, pela impossibilidade de liberação de vagas pelo Ministério da Educação (MEC) para a realização de concursos. Com isso, o quadro tendeu ao envelhecimento e houve inúmeros casos de aposentadorias sem reposição, além de planos de demissão voluntárias incentivadas, em alguns períodos. Além disso, grande parte dos servidores havia alcançado o topo das tabelas remuneratórias. Não existia, nessa época, quase nenhum incentivo para participar de cursos, treinamentos, aperfeiçoamentos a não ser por motivações pessoais.

Nesse contexto, o advento do PPCTAE trouxe fôlego novo à política de capacitação ao expandir as tabelas salariais em mais níveis e, principalmente, ao conceder Incentivos à Qualificação (Educação Formal) que variam de $10 \%$ a $75 \%$ de aumento salarial e à inclusão da Progressão Funcional por Capacitação (até 4 níveis dentro do mesmo cargo) decorrente da obtenção de certificados em programas de capacitação. Essas ações incluídas no Plano podem ser consideradas estratégicas, no sentido em que incentivaram a quase totalidade dos servidores para buscarem a capacitação.

\section{Conclusões}

O contexto histórico que envolveu a criação da Coordenadoria de Capacitação no âmbito da Secretaria de Recursos Humanos da UnB, em 1995, em quase nada se assemelha à realidade dos dias atuais. $O$ artigo analisou as principais alterações nos processos de capacitação da Universidade de Brasília (UnB), entre 1995 e 2015, em face da literatura de gestão estratégica de pessoas, tomando como marco inicial o advento do Plano Diretor de Reforma do Aparelho do Estado editado pelo então Ministério da Administração e Reforma do Estado (MARE), em 1995. Os efeitos da Reforma nas políticas de capacitação dos órgãos tiveram início a partir da publicação de Decretos que, a partir de 1998, instituíram a política nacional de capacitação dos servidores da Administração Pública. Outros pontos de referência foram os Decretos de 2006, que instituíram e regulamentaram a política e as diretrizes para o desenvolvimento de pessoal.

O esforço para alcance dos objetivos propostos, a fim de responder a questão orientadora deste artigo, impôs de imediato a necessidade de se estabelecer relação com um embasamento teórico consistente que espelhasse as ações que envolveram capacitação no âmbito da Universidade de Brasília (UnB) nos últimos 20 anos. Buscou-se, para tanto, relacionar essas ações com os Modelos de Administração Pública consolidados na literatura, aprofundando-se nas publicações de gestão estratégica de pessoas.

Os quatro Modelos de Administração Pública (Patrimonialista, Burocrático, Gerencial e Estratégico), não excludentes em suas características, mas bastante diversos em suas propostas de revolução de estruturas, foram aqui, didaticamente utilizados como termômetros nos procedimentos, nas decisões, planejamentos, execuções e controles dos programas de treinamento e capacitação que a UnB desenvolveu nesse período. Dessa forma, foi possível mapear as atividades desde a criação da Coordenadoria de Capacitação (PROCAP), criação essa já resultado das orientações da Reforma, e espelhá-las com as principais características dos Modelos teóricos.

Resgatou-se, por exemplo, que as condições de trabalho oferecidas aos trabalhadores, do início da Universidade (década de 1960) até meados dos anos 1970 eram consideradas melhores que as atuais. A deterioração da própria Universidade como estrutura foi diversas vezes apontada como um dos pontos históricos negativos. No entanto, o aspecto considerado como fundamentador para a definição do cenário atual da Universidade foi a falta de políticas estruturadas. Esse ponto de vista foi compartilhado por quase todos os participantes, e também pôde ser notado em muitas das falas registradas em atas de reuniões colegiadas.

As perdas econômicas, as falhas nas decisões de investimento, a má conservação das instalações físicas, a ausência de ações mais empreendedoras, a falta de foco nos resultados e até mesmo o que não depende de recurso financeiro (como a revogação da flexibilização de jornada de trabalho dos técnicos), foram aspectos atribuídos aos administradores que estiveram à frente da UnB durante o período. Os resultados apontaram que a gestão UnB é considerada conservadora e tradicional em suas ações e decisões, apresentando, eventualmente, comportamentos clientelistas, características do modelo patrimonialista.

No que tange aos procedimentos e atendimentos, a Universidade tende a padronizações ultrapassadas. A pouca habilidade na utilização dos recursos, principalmente os tecnológicos, por falta de conhecimentos específicos é vista como um contracenso, por tratar-se de uma Instituição de Ensino. Foram citados exemplos de comportamentos excessivamente arraigados às normas, com pouca ou nenhuma margem de flexibilidade. Crê- 
se que não são comuns práticas que busquem a maximização de tempo de serviço e de recursos sem que haja perda de qualidade nos serviços, o que revela característica típica do modelo burocrático moderno.

Atualmente o modelo por competências ou modelo de administração estratégica parece ser o que mais reúne ferramentas capazes de guarnecer a Administração Pública. A racionalização dos gastos e a melhoria do desempenho dos quadros funcionais são apontadas como os principais atributos desejáveis em um gestor estratégico. No entanto, os resultados obtidos parecem mostrar que ainda não há, na Universidade de Brasília, conhecimento técnico e ferramentas nas unidades de capacitação para a efetiva implantação de modelos de gestão por competências, assim como não há consenso por parte da Administração Superior em torno da necessidade de implantação de um modelo de gestão por competências.

Sobre a política de capacitação em si, o que se destaca é a percepção da necessidade de uma atuação voltada para a orientação e apoio técnico nas atividades de capacitação, assim como para a coordenação entre os setores, visando o alinhamento de critérios de decisão e a difusão de melhores práticas de treinamento. Mostra-se inviável exigir um corpo técnico capacitado sem que as condições para tal sejam disponibilizadas, e não são condições mínimas.

Essa denominada "falta de alinhamento" entre discurso e ação decorre, em grande parte da descontinuidade no curso das políticas estabelecidas na autarquia para desenvolver seu pessoal e essa descontinuidade, por sua vez, tem relação com o modelo de Administração Pública que o Brasil adota.

Portanto, Que modelo é esse? Conclui-se que, de todos os aspectos, o que mais mereceu destaque em termos de resultado, foi o fato de até os dias atuais, ou seja, 20 anos após o Plano Diretor de Reforma do Aparelho do Estado, a UnB não ter formalizado uma Resolução para instituir sua Política de Capacitação, que visa sua implementação dentro de uma lógica estratégica.

De acordo com Fonseca (2013), organizações que não possuem planos estratégicos formais também são capazes de atuar efetivamente, de forma proativa na oferta de soluções de treinamento, desde que percebidas como legítimas. O respaldo estratégico é um meio para o alcance e manutenção da legitimidade na organização, a qual se torna o principal objetivo das unidades de gestão de pessoas.

No entanto, esta lacuna na legislação da UnB parece reafirmar a falta de um olhar mais atento por parte da Administração sobre esta questão. Admitir que o servidor técnico-administrativo não dispõe dos mesmos recursos de capacitação que o professor, posto que as instituições de fomento à carreira docente publicam editais para este fim é um primeiro passo.

\section{REFERÊNCIAS}

BARBOSA, E.A. Burocracia e processo decisório na administração das universidades federais brasileiras: um estudo de caso. Dissertação (Mestrado em Educação) -Unicamp, São Paulo, 1981.115p.

Bardin L. (1977) Análise de conteúdo. Lisboa: Edições 70
Borges-Andrade, J. E., \& de Oliveira-Castro, G. A. (1996). Treinamento e desenvolvimento: reflexões sobre suas pesquisas científicas. Revista de Administração da Universidade de São Paulo, 31(2).

BRASIL, R. F. D. I. Ministério da Administração Federal e Reforma do Estado (1995).A Reforma do aparelho do estado e as mudanças constitucionais: síntese \& respostas a dúvidas mais comuns Ministério da Administração Federal e Reforma do Estado. Brasília: MARE, 23p.(Cadernos MARE da reforma do Estado)

CAMÕES, M. R. S. Análise do Processo de Implementação da Política Nacional de Desenvolvimento de Pessoal. Dissertação (mestrado) Programa de Pós-Graduação em Administração, Universidade de Brasília, Brasília, 2013.

Cardoso Jr, J. C. (2011). Planejamento governamental e gestão pública no Brasil: elementos para ressignificar o debate e capacitar o Estado. Texto para discussão n. 1584, IPEA. Brasília, março.

Carvalho, J. M. D. (2000). Rui Barbosa e a razão clientelista. Dados, 43(1), 83-117.

CUNHA, L.A. A Universidade brasileira - entre o taylorismo e a anarquia. Revista Brasileira de Educação, Cidade, n. 10, p. 90-96, jan./abr.1999. Disponível em: < http://educa.fcc.org.br/pdf/rbedu/n10/n10a07.pdf>. Acesso em: 30 de janeiro 2017.

Danhke, G.L. (1989). Investigacíon y comunicación. In: Fernández-Collado, C; Danhke, G.L. (Comps). La Comunicación humana: Ciência social. México: McGraw-Hill. p. 385-454.

De Paula, A. P. P. (2005). Por uma nova gestão pública: limites e potencialidades da experiência contemporânea. FGV Editora.

Dos Santos, W. (2006). O ex-Leviatã brasileiro: do voto disperso ao clientelismo concentrado. Editora Record.

Federal, S. (1988). Constituição da república federativa do Brasil. Brasília: Senado.

Ferlie, E. (1996). The new public management in action. Oxford University Press, USA.

Fonseca, D. R. D. (2013). Autonomia de unidades de gestão de pessoas para desempenho das atividades estratégicas de capacitação na administração pública federal. Dissertação (mestrado) - Programa de Pós-Graduação em Administração, Universidade de Brasília, Brasília

FONSECA, Diogo Ribeiro da et al . Autonomia para gestão estratégica de pessoas no setor público federal: perspectivas de análise e agenda de pesquisa. Rev. Adm. Pública, Rio de Janeiro, v. 47, n. 6, p. 1451 . 1475, Dez. $2013 \quad$ Disponível em <http://www.scielo.br/scielo.php?script=sci_arttext\&pid=S0034-

$76122013000600006 \&$ lng =en\&nrm=iso $>$. access on 30 Jan. 2017. http://dx.doi.org/10.1590/S0034-76122013000600006.

Freitas, H., Cunha Jr, M., \& Moscarola, J. (1997). Aplicação de sistema de software para auxílio na análise de conteúdo. Revista de Administração da USP, 32(3), 97-109

Freitas, W.R.S., Jabbour, C. J.C., \& Santos, F.C.A. (2011). Continuing the evolution: towards sustainable HRM and sustainable organizations. Business strategy series, 12(5), 226-234.

Gouvêa, G. P. (1994). Burocracia e elites burocráticas no Brasil. Editora Paulicéia.

Guimarães, T. D. A. (2000). A nova administração pública e a abordagem da competência. Revista de Administração Pública. Rio de Janeiro, maio/junho, V. 34 (3).

Hood, C. (1991). A public management for all seasons?. Public administration, 69(1), 3-19.

Kinzo, M. D. A. G. (2001). A democratização brasileira: um balanço do processo político desde a transição. São Paulo em perspectiva, 15(4), 3-12. Lastres, H. M. (1999). Informação e conhecimento na nova ordem mundial. IBICT-Instituto Brasileiro de Informação em Ciência e Tecnologia. V.28(1).

Meneses, P., Zerbini, T., \& Abbad, G. (2010). Avaliação de efeitos de treinamento, desenvolvimento e educação de pessoas. Meneses $P$, Zerbini T, Abbad G. Manual de treinamento organizacional. Porto Alegre: Artmed.

Mises, L. V. (1944). Bureaucracy. Yale.

Nabuco, J. (1977). O Abolicionismo. Quarta Edição. Vozes/INL, Petrópolis, RJ.

Oliveira, G. A. (1970). A burocracia weberiana e a administração federal brasileira. Revista de Administração Pública, 4(2), 47-74.

Pacheco, R. S. (2002). Política de recursos humanos para a reforma gerencial: realizações do período 1995-2002. Revista do Serviço Público. Brasília: ENAP, n.4, p. 78-105, out/dez.

Pereira, L. C. B. (2015). Da administração pública burocrática à gerencial. Revista do Serviço público, 47(1), 07-40.

Pereira, L. C. B. (1997). A reforma do Estado dos anos 90: lógica e mecanismos de controle (Vol. 1). MARE, Ministério da Administração Federal e Reforma do Estado.

Pereira, L. C. B. (1998). Exposição no Senado sobre a reforma da administração pública (Vol. 3). Ministério da Administração Federal e Reforma do Estado.

Pereira, L. C. B. (1998). Reforma do Estado para a cidadania: a reforma gerencial brasileira na perspectiva internacional. Editora 34. 
Pilati, R. História e importância de TD\&E. In: Borges-Andrade, J. E., da Silva Abbad, G., \& Mourão, L. (2009).Treinamento, desenvolvimento e educação em organizações e trabalho. Artmed Editora. p.159-176

Pollitt, C. (1990). Managerialism and the public services: The Anglo-American experience. Basil Blackwell.

Prates, A. A. P. (2007). Administração pública e burocracia. Sistema político brasileiro: uma introdução. Rio de Janeiro: Konrad Adenauer-Stiftung.

Ramos, A. G. (1977). Cartilha de Aprendiz de Sociólogo. RJ., AG.

Ramos, A. G. (1983). Administração e contexto brasileiro: esboço de uma teoria geral da administração (Vol. 323, p. 313). Rio de Janeiro: Fundação Getulio Vargas.

RIZZATTI, G e DOBES, C.E.I. A complexidade do processo decisório em universidades. In: MELO, P.A.; COLOSSI, N. (Orgs.). (2004) Cenários da gestão universitária na contemporaneidade. Florianópolis: Insular. p. 185192.

Sampieri, H. (2006). Roberto Metodología de la Investigación/Roberto Hernández Sampieri, Carlos Fernández Collado, Pilar Baptista Lucio. São Paulo, McGraw-Hill
Silva, A. H., \& Fossá, M. I. T. (2015). Análise de Conteúdo: Exemplo de aplicação da técnica para análise de dados qualitativos. Qualitas Revista Eletrônica, 16(1).

Souza, E.C.L. A capacitação administrativa e a formação de gestores governamentais. (2002) Revista de Administração Pública. Rio de Janeiro: FGV, v. 36, n. 1, p. 73-88, jan/fev .

Weber, M. (2004). A ética protestante e o espírito do capitalismo. São Paulo: Companhia das Letras.

Weber, M. (1994). Economia e sociedade: fundamentos da sociologia compreensiva (Vol. 1). Editora Universidade de Brasília.

Weber, J. G., Zanetti, M. C. V., \& de Melo, M. A. C. (2015). Capacitação E Avaliação Dos Servidores Técnico Administrativos Em Educação Da UFJF A Partir Da Política Nacional De Desenvolvimento De Pessoal Pndp: Uma Análise A Partir Dos Servidores. Gestão Pública: Práticas e Desafios-ISSN: 2177-1243,4(2) 